\title{
Giant Cell Tumor on Tendon Sheath of the Hand: The Incidence of Recurrence, Functional Outcomes and a Literature Review
}

\author{
Kastanis G ${ }^{* 1}$, Bachlitzanaki $\mathbf{M}^{2}$, Kapsetakis $\mathbf{P}^{1}$, Christoforidis $\mathbf{C}^{1}$, Chaniotakis ${ }^{1}$, Pantouvaki A ${ }^{3}$ \\ ${ }^{1}$ Department of Orthopaedic, General Hospital of Heraklion -Venizeleio, Crete, Greece \\ ${ }^{2}$ Department of Medical Oncology, General Hospital of Heraklion -Venizeleio, Crete, Greece \\ ${ }^{3}$ Department of Physiotherapy, General Hospital of Heraklion -Venizeleio, Crete, Greece \\ *Corresponding Author: Grigorios Kastanis, email: kastanisg@gmail.com
}

Received: 09 December 2020;

Accepted: 22 December 2020;

Published: 28 December 2020

\begin{abstract}
Giant Cell Tumor on Tendon Sheath (GCTTS) of the hand is a benign nodular tumor originated from tendon sheath of the tendons and the joints and is the second most common soft tissue tumor of the hand after ganglion cyst. The aim of this study is to evaluate 79 cases of giant cell tumor of tendon sheath of the hand and to analyze the postoperative functional outcomes and recurrence rate of the tumor in a mean period of five years follow up. Material and Methods: Fifty five subjects were females and twenty four males with an average age of 38,8 years-old (range23-65 years old) were included in this study. The most frequent location of tumor was the index finger ( $32 / 79$ patients, 40,5\%). The majority of patients was presented in outpatient's clinic for a painless swelling on volar side of the digit, while only $13(16,45 \%)$ patients presented for painful mass and numbness of the digit in 7(8,9\%) cases. All cases were categorized by Al-Qattan classification system with type I lesion in 51(64,5\%) cases and type II in $28(35,5 \%$ ) cases. Dimension of tumors macroscopically varied from $0,4 \mathrm{~cm}$ to $5 \mathrm{~cm}$. In 12 cases we reconstructed the A2 pulley to avoid bowstring deformity and eventual postoperative loss of hand function. In 12 cases we reconstructed the A2 pulley to avoid bowstring deformity and eventual postoperative loss of hand function. 8 patents with bone erosion underwent postoperatively complementary local radiotherapy. A standard protocol of rehabilitation was performed in all patients. Results: Results were evaluated according to complications, range of motion, Quick Dash Score and functional satisfaction of patients in a mean follow-up of 49 months. Two major complications presented in this study: 5 cases with transitional neuroapraxia and 6 cases with recurrence of the tumor with a mean of postsurgical period 14,8 months. Finally at last assessment the mean Quick Dash Score was 4,5 (range from 0-11,4) the range of motion was fully recovered in 73 patients while patient's satisfaction rated from "very satisfied" in 58(73,4\%) cases, "satisfied" in $17(21,5)$ and "dissatisfied" in $4(5,1 \%)$ patients. Conclusions: Giant cell tumor of tendon sheath of the hand is a common tumor which presents a high incidence of recurrence in different populations of patients. The goal of treatment is to reduce the recurrence rate and restore a functional hand. The operation procedure should be well planned preoperatively, the tumor must excised en block, dissection must be under surgical loop and must be emphasized to remove satellite lesion while when patients present increased risk factors or inadequate excision of the mass, postoperative radiotherapy is performed.
\end{abstract}

Keyword: Giant cell tumors, tendon sheath, hand tumor, recurrence

\section{Introduction}

Giant Cell Tumor on Tendon Sheath (GCTTS) in the hand is a benign nodular tumor which originates from the tendon sheath of the tendons and the joints ${ }^{[1]}$. It is the most common soft tissue tumor of the hand after ganglion cyst ${ }^{[2]}$. GCTTS belongs to a rare group of proliferative disorder of the synovial joints and tendon sheaths and for these reason it has been referred to the literature by a diversity of titles such as benign syn-ovioma, fibrous xanthoma, localized villonodular synovitis, sclerosing hemangioma, fibrous histocytoma of synovium, and pigmented villonodular tenosynovitis ${ }^{[3]}$. GCTTS is a painless tumor with a slow-growing period for clinical manifestation which varies from months to years ${ }^{[4]}$. Generally it appears in patients between 30 and 50 years of age and affects more commonly women than men ${ }^{[5,6]}$.

Initial classification of the tumor described from Byers et al in two major types, the localizated nodular type (common in hand) and the diffuse type (common in other joints) ${ }^{[25]}$. The first type is a well delineated lobulated swelling in majority of cases, extrarticular and benign which appears most common in volar surface on sheaths flexor tendon of the hand ${ }^{[2]}$. The diffuse type is an infiltrative mass in plurality of cases, intra-articular with 
multiple satellite lesion with preference for large joints and may produce limited range of motion ${ }^{[6,7]}$. Al-Qattan (2001) has analyzed the postoperative recurrence of the tumor and proposed a new classification system for GCTTS consisted of two main types depending on whether the entire tumor was, or not surrounded by one pseudocapsule, as assessed during surgical procedure. Type I is a single tumor which is round or multi lobulated and type II is appeared as two or more distinct tumors which are not joined together. Each type was sub-classified according to the thickness of the capsule, lobulation of the tumor, the presence of satellite lesions, and the diffuse or multicenteric nature of the tumor ${ }^{[12]}$.

Although pathogenesis of the tumor is not clear, many etiological factors have been described in literature such as infection, vascular disorders, osteoclastic proliferation, immune mechanisms, inflammation, neoplasia and metabolic disorders, sequel of bleeding after trauma ${ }^{[4,8]}$. The most common accepting theory is that GCTTS originates from a reactive or regenerate hyperplasia associated with an inflammatory process ${ }^{[9,13]}$.

Primary step in diagnosis of GCTTS is clinical examination and patient medical history. Standard radiography is useful when tumor produces erosion in cortical area of the phalange or invades medullary canal ${ }^{[10]}$. Ultrasonography or magnetic resonance imaging(MRI) are important tools both in diagnosis of the lesion and in management of the preoperative planning ${ }^{[11]}$.

The aim of this study is to evaluate 79 cases of giant cell tumor of tendon sheath of the hand and to analyze the postoperative functional outcomes and recurrence rate of the tumor in a mean period of five years follow up.

\section{Material \& Methods}

The study was performed at the Orthopaedic department of General Hospital of Heraklion-"Venizeleio «for 7 years from 2012 to 2019. The Institutional Ethical Committee approved the study. Every soft tissue tumor of the hand was inserted into a database using a conventionalize protocol. The protocol format included demographics elements, localization of the tumor, preoperative imaging examinations, surgical details (Al-Qattan classification system), and following-up data. At the final examination the complication rates were assessed (postoperative recurrence, infection, and digital neuropathy), range of motion, functional outcomes and satisfaction of patients.

Table I. Anatomical distribution of the GCTTS

\begin{tabular}{|l|l|l|l|l|l|l|l|l|}
\hline & $\begin{array}{l}\text { MCP } \\
\text { Joint }\end{array}$ & $\begin{array}{l}\text { Proximal } \\
\text { Phalanx }\end{array}$ & $\begin{array}{l}\text { PIP } \\
\text { Joint }\end{array}$ & $\begin{array}{l}\text { Middle } \\
\text { Phalanx }\end{array}$ & $\begin{array}{l}\text { DIP } \\
\text { Joint }\end{array}$ & $\begin{array}{l}\text { Distal } \\
\text { Phalanx }\end{array}$ & $\begin{array}{l}\text { Thumb } \\
\text { IP Joint }\end{array}$ & $\begin{array}{l}\text { Thumb Proximal } \\
\text { Phalanx }\end{array}$ \\
\hline Volar & 6 & 25 & 5 & 13 & 11 & 4 & 1 & 1 \\
\hline Dorsal & & & 1 & 4 & 1 & & 1 & \\
\hline Lateral & & 3 & 2 & 1 & & & & \\
\hline Total & 6 & 28 & 8 & 18 & 12 & 4 & 2 & 1 \\
\hline
\end{tabular}

All patients were performed radiographic examination which revealed in 8 cases bony erosions. Sixty five patients underwent magnetic resonance imaging with the results showing a low signal on T1WIs and T2WIs, while ultrasonography in 14 cases showed a hypoechogenic image.

The operative excision was performed with $4,5 \mathrm{x}$ magnification loupes under brachial tourniquet and regional anesthesia. Surgical approach of the mass depended on the location so volar digital Brunner approach performed when the tumor was volarly, midlateral in lateral location of tumor and dorsal incision in dorsal localization. Extreme attention was given to excise the tumor en block without destroying the capsule, with scope to avoid
Seventy nine patients were included in this study. Fifty five were females and twenty four males with an average age of 38,8 years-old (range23-65yrs). The mean duration of symptoms before excision ranged from eight months to ten years. The most frequent location of tumor was in index finger(32/79 patients, 40,5\%), while the other distribution of the tumor was in thumb(3/79 patients, $3,8 \%)$, middle (19/79 patients, $24 \%$ ) ring(14/79 patients, $17,8 \%)$, and little finger(11/79 patients, 13,9\%) (Fig.1). The majority of patients was presented in outpatient's department for a painless swelling on volar side of the digits, while only $13(16,45 \%)$ patients presented for painful mass and numbness of the digit in $7(8,9 \%)$ cases. The dominant hand was affected in 48 cases $(60,75 \%)$. Among causes, $17(21,5 \%)$ cases referred a past trauma, 5(6,3\%) cases had rheumatic arthritis and the rest $57(72,2 \%)$ cases had unknown etiology.

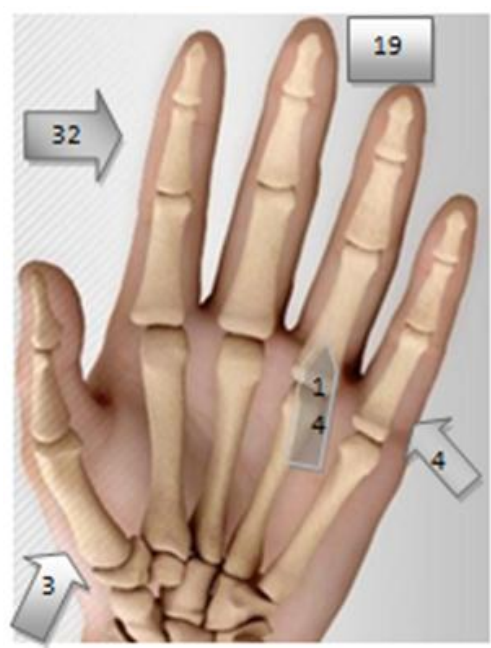

Figure 1: Anatomical distribution of GCTTS in 79 cases: Thumb (3), Index (32), Middle (19), Ring (14), Little finger (11) (grey arrow).

Determining the location of the tumor, depending on the anatomical landmark of the hand was in metacarpophalangeal joint $(7,6 \%)$, proximal phalanx $(35,44 \%)$, proximal interphalangeal joint $(10,12 \%)$, middle phalanx $(22,8 \%)$, distal interphalangeal joint $(15,19 \%)$, distal phalanx $(5 \%)$, proximal phalanx of the thump $(1,35 \%)$ and interphalangeal joint of the thumb(2,53), while the localization was in volar surface $(83,6 \%)$, dorsal $(8,9 \%)$ and lateral $(7,6 \%)$ (Table I). damage in digital neurovascular element and tendons and to discover and remove all satellite lesions (Fig. 2). Dimension of tumors macroscopically varied from $0,4 \mathrm{~cm}$ to $5 \mathrm{~cm}$ ). In 12 cases we reconstructed the A2 pulley to avoid bowstring deformity and eventually postoperative loss of hand function. All cases were categorized by Al-Qattan classification system in which type I lesion was in $51(64,5 \%$ ) cases and type II in $28(35,5 \%)$ cases (Table II). The majority of tumors detected type I(51/79 - 64,5\%) more than type $\mathrm{II}(28 / 79-35,5 \%)$. Microscopically tumors contained giant cells, histiocytes and haemosiderin. Patents with bone erosion underwent complementary local radiotherapy. 
Table II: Al Qattan classification in 79 cases

\begin{tabular}{|c|c|c|}
\hline Type & & Subtype \\
\hline I. & $\begin{array}{l}\text { The entire volume is surrounded by a pseudo } \\
\text { - membrane } 51(64,5 \%) \text { pts }\end{array}$ & $\begin{array}{l}\text { a. } \\
\text { b. Solitary nodule in a thick whitish membrane. } 15 / 79 \text { pts } \\
\text { c. } \quad \text { Lobar lesion surrounded by a common pseudo membrane } 9 / 79 \text { pts }\end{array}$ \\
\hline II. & $\begin{array}{l}\text { The entire volume is not surrounded by a } \\
\text { membrane } 28(35,5 \%) \text { pts }\end{array}$ & $\begin{array}{l}\text { a. A main node (in a pseudo-membrane), which is accompagnied by a separate } \\
\text { satellite lesion. } 17 / 79 \mathrm{pts} \\
\text { b. Widespread type with many granular tumors without membrane. } 9 / 79 \mathrm{pts} \\
\text { c. Polycentric type with many separate lesions in the same finger } 2 / 79 \mathrm{pts}\end{array}$ \\
\hline
\end{tabular}

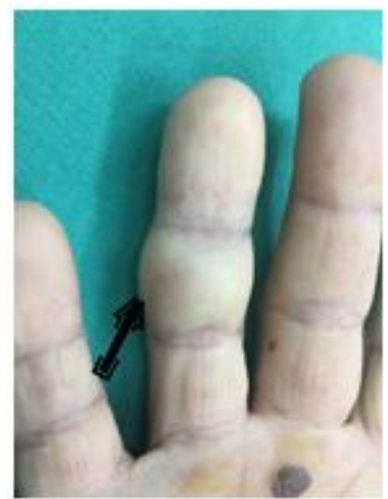

(a)

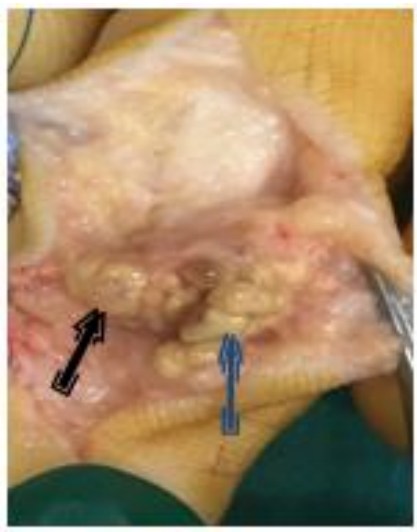

(b)

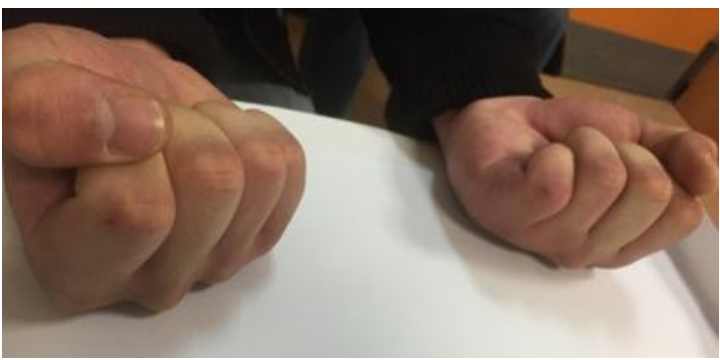

(e)

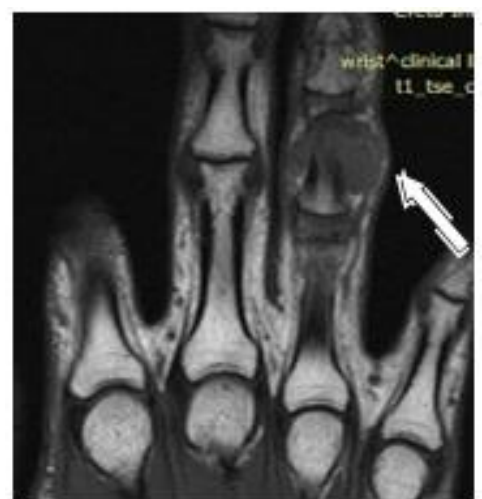

(b)

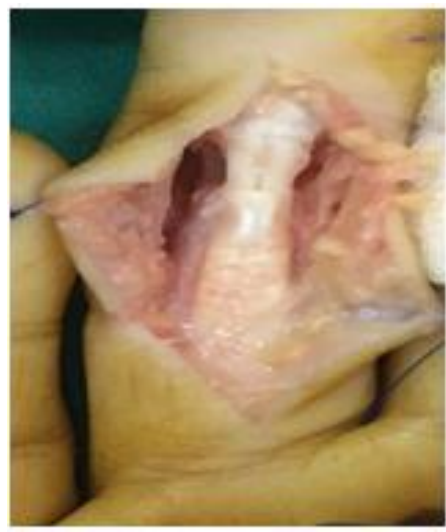

(d)

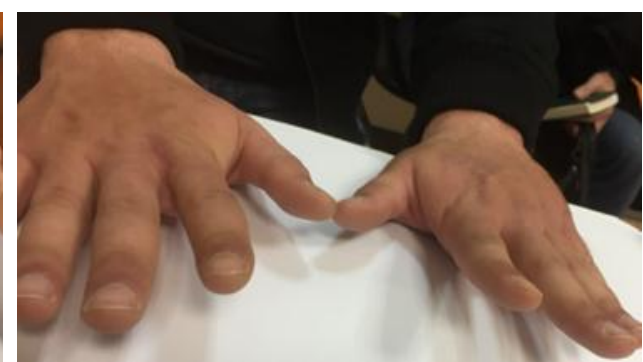

(f)

Figure 2: Man 34 years old(a) with a swelling on volar middle phalanx of right ring finger for 3 years (black arrow). MR I(b) appears GCTTS (white arrow). Tumor over flexors tendons (black arrow) with lateral extension (blue arrow) which classified as type IIb (AlQattan)(c). Full excision of the tumor (d). At final follow-up (50 months) full range of motion without recurrence (e,f)

Postoperatively sutures were removed at 10-12 days and a standard protocol of rehabilitation was performed in all patients. Physiotherapy treatments were delivered twice a week. The main goal in the first sessions was the decrease of post-operative edema and the prevention of scar tissue formation. Patient was trained to perform scar massage on his own, passive and self assistive finger flexion and extension for 2 weeks and then when pain and edema decreased active range of motion was performed in pain limit. Patients received 20 sessions of physiotherapy treatment in order to eliminate scar formation and enhance the range of movement and then were assessed every month for six months follow-up to secure that there was no dysfunction.

\section{Results}

The Mean follow-up is 49 months (range from 14 months to 6 years). None of patients missed the last re-examination. Results were evaluated according to complications, range of motion, Quick Dash Score and functional satisfaction of patients. We classified complications in two categories, complications among the surgery (infection, skin necrosis, neurovascular damage) and postoperative 
complications (recurrence of tumor, stiffness). We observed 5 cases in the first category with transitional neuroapraxia. In three cases the mass was localizated in lateral size and in two cases the tumor was localizated volarly and has lateral extension. All cases recovered after a mean period of 4 months (range 8 weeks to 6 months). Three cases developed infection which treated with antibiotics for 2 weeks.

Recurrences were present in 6 patients, at 5,9,12,16,20,27 months after the surgery. Five patients underwent a second procedure which accompanied with local radiotherapy. None of these patients had initial bone erosion and were classified as type I in 1 cases and type II in 5 cases. Among localization one was at proximal phalanx, two at proximal interphalangeal joint, one at middle phalanx and 2 at distal interphalangeal joint. Four of these cases had lateral extension of the tumor and three of them were in contact with digital neurovascular bandle. None of these patients developed new recurrence of the tumor.

At final examination the mean Quick Dash Score was 4,5 (range from 0-11,4). The range of motion was fully recovered in 73 patients while in 6 patients presented a mean restriction at the flexion $6^{\circ}, 8^{\circ}, 10^{\circ}$ of distal interphalangeal compared with the contralateral hand. The other two cases presented a restriction of $5^{\circ}, 7^{\circ}$ of proximal interphalangeal joint. Three of them suffered from rheumatic arthritis and two cases had second operation because of recurrence of the tumor. Finally, the patient's satisfaction recorded as "very satisfied" in $58(73,4 \%)$ cases, " satisfied" in 17(21,5) and "dissatisfied" in 4(5,1\%) patients (Fig 3).

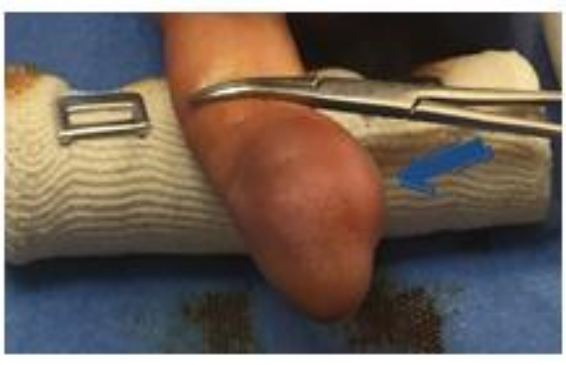

(a)

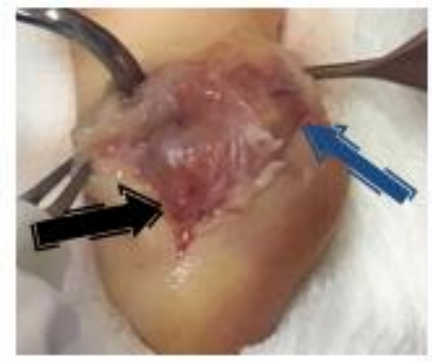

(b)

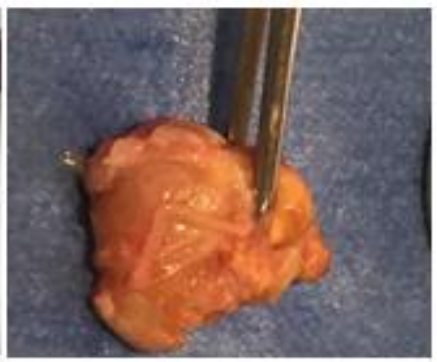

(c)

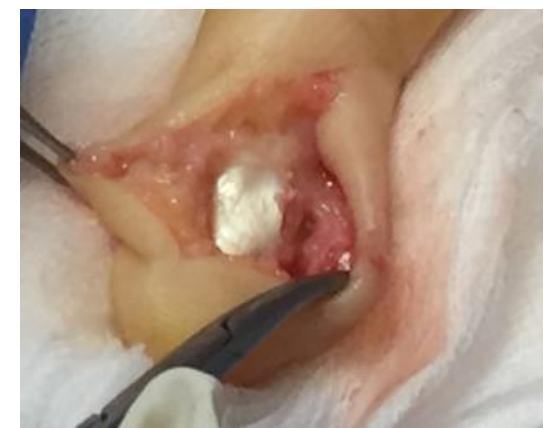

(d)

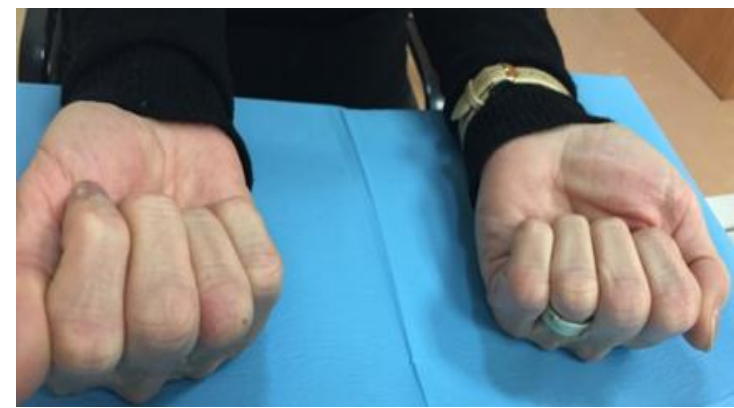

(e)

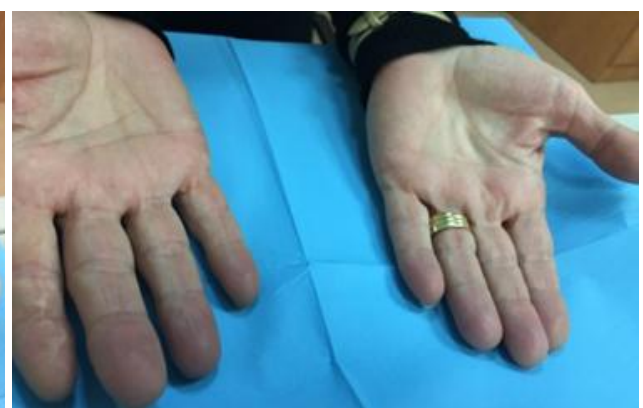

(f)

Figure 3: Female 58 years old with a painful swelling (blue arrow) on volar distal phalanx of right index finger for ten years(a). Tumor localizated (b) on flexor profundus tendon (black arrow) of index finger over attaching to the distal phalanx with lateral extension(blue arrow). GCTTS type Ia (Al- Qattan)(c). Full excision of the tumor (d). At final follow-up (52 months) full range of motion without recurrence $(e, f)$

\section{Discussion}

From the first description in the literature by Chassaignac (1852) as "malignant tumor of tendon sheaths" to its final name from Targett (1897) as "giant cell tumor of tendon sheath" tumor has been described by many titles with the result that there is not clear definition of the disease ${ }^{[11,14,15]}$. It is the second most common type of soft tissue s tumor of the hand after gaglion cyst, and appears in general as solitary benign painless, slow-growing tumor. In rare cases tumor can produce severe restriction of motion ${ }^{[18]}$. In literature, this lesion has also been reported in wrist, shoulder, hip, knee and foot ${ }^{[17]}$. GSTTS originates from the tenosynosheath, bursa and joint synovium ${ }^{[16]}$. Histopathologically the tumor presents fusiform cells, fibrotic tissue elements, histiocytes with cholesterol, multinuclear giant cell and haemosiderin ${ }^{[19]}$. Initial histological characteristics of cellularity and mitosis were considered important elements to postoperative recurrence of tumor finally reported that is not affected by these factors ${ }^{[12]}$. Rao et al (1984) found in their own study high incidence of recurrence in tumors with increased mitotic activity and suggested that there 
was no relation between the initial number of mitosis and recurrence but all recurrence lesion showed increased mitotic activity ${ }^{[18]}$. Instead Monaghan et al in 51 patients found that mitotic and apoptotic features are common in GSTTS but they do not indicate the recurrence of the tumor ${ }^{[2]}$. Recent advances in molecular oncology by Groves et al showed that giant cell tumors nm23 negative are more aggressive and have increased recurrence rate ${ }^{[20]}$. Lorea et al (2004) in their study reported that there is no correlation between $\mathrm{nm} 23 \mathrm{H} 1$ expression and risk for recurrence [28]

Giant cell tumor of tendon sheaths of the hand can occur in any age predominant between the third and fifth decade of life with a great incidence of 2 per 100.000 per year between 40-50 years especially in female ${ }^{[8]}$. In majority of cases it is diagnosed in a single joint while the incidence of poliarticular comprise is less than $1 \%{ }^{[21]}$. Preoperative imaging examination must be performed with target to decreased differential diagnosis and to discover other lesions (bone erosion, subchondral cyst) ${ }^{[13]}$. Ultrasonography usually distinguish a hypoechogenic mass but has also been described a hyperechogenic lesion ${ }^{[22]}$. Additional MRI shows a low signal intensity on both T1-T2 weighted images of the lesion but principal role of the specific examination is early diagnosis of GSTTS, accurate size and extend of the lesion and to differentiate between villonodular synovitis, synovial chondromatosis and synovial sarcoma ${ }^{[23]}$. Lautenbach et al(2013) in 84 cases of GCTTS suggest that none of the soft tissue imaging methods(U/S MRI) prevail in diagnosis or for the preoperative planning ${ }^{[24]}$. On the contrary Wang et al(2017) investigate the value of the MRI in both types of GCTTS in 38 patients and suggest that the specific imaging examination is an optimal modality for preoperative assessment of tumor size, extent and invasion of adjacent joint and Tenosynovial space ${ }^{[26]}$. We postulate that these examination offer element about the lesion (size, extension, bony erosion) but the final diagnosis offers histopathological confirmation.

Although wide marginal surgical excision of the tumor is the gold standard of treatment for both types of GCTTS the important risk of this lesion is recurrence and joint damage and particular(especially) caution must need in management of diffuse type of tumor because of increased rate of recurrence ${ }^{[27]}$. Local recurrence of the tumor has been reported in literature varied from $4,7 \%$ to $45 \%{ }^{[5,12,13,27,29,30]}$. Fotiadis et al(2011) proposed the risk factors of GCTTS recurrence, location at the distal interphalangeal joint of the finger or the thumb, incomplete excision, bone erosion, cellularity and mitotic activity on histopathological examination, proximity to the arthritic joint, tumors which are $\mathrm{nm} 23$ negative and type II tumors ${ }^{[5]}$. Reilly and Grover suggest that bone erosion might a factor for recurrence ${ }^{[13,20]}$. Kitagawa and Al- Qattan do not support this theory and defend that bony erosion caused from the pressure effect of the tumor and is not invasion ${ }^{[12,32]}$. In 8 patients in our study with bony erosion none appeared recurrence, but all of them underwent radiotherapy.

Anatomical location like interphalangeal joints of the finger and thumb localization is a factor for reccurence ${ }^{[29]}$. Reilly et al reported when tumors localizated in DIP joint and thumb IP joint, had an incidence of recurrence $79 \%$ and those with dorsal localization $34 \%$, while Williams et al reported 3 cases in 34 patients with GSTTS localizated into the thumb ${ }^{[13,33]}$. Ozben et al presented in their study recurrences at the PIP and DIP joint but none after excision of 11 tumors from the thump and in dorsally localized tumors ${ }^{[30]}$. In our recurrence rate only 4 cases were localizated in interphalangeal joints ( 2 in PIP and 2 in DIP joint) but none of the cases with localization in thumb presented recurrence.
Kitagawa et al (2004) investigated the involvement of tumor with digital neurovascular band associated with increased rate and supported that vicinity of tumor with neurovascular elements makes the complete excision of the tumor difficult and maybe a factor of recurrence ${ }^{[32]}$. Di Grazie et al reported 3 recurrences in 7 cases with neurovascular involvement, while Ozben et al referred in their study neurovascular intricacy did not increase recurrence risk ${ }^{[29,30]}$. Three patients from our recurrence had involvement with digital neurovascular bandle.

Al-Qattan suggests that type II tumors had increased recurrence rates ${ }^{[12]}$. This theory is supported by other investigators as well and in our study 5 patients were classified as type II ${ }^{[4,5,29]}$. On the contrary Ozben supported that type II GCTTS don t show an increased recurrence rate ${ }^{[30]}$.

Ikeda and Kitagawa suggested parameters to decreased recurrences such as the use of a tourniquet, use of magnification devices like loupe or operating microscope, and meticulous surgical dissection and thorough exploration and clearance of all the satellite lesions ${ }^{[25,32]}$. If the tendon was involved with tumor, must be sacrificed and need reconstruction ${ }^{[25]}$. Debridement and absolute curettage are needed in lesions involving the adjacent bone and bone cement or graft must be used, while in cases with involvement of the skin an elliptical excision of the involved area followed by primary closure or skin grafting when the defect is larger is recommended ${ }^{[32,35]}$.

Postoperative Radiotherapy has been suggested after inadequate excision and in patients with increased risk factors of GCTTS recurrence ${ }^{[34]}$. Kotwal et al. reported no recurrence in 14 patients with postoperative radiotherapy and suggested the use of 20 Gy in daily doses of $2 \mathrm{~Gy}$, On the contrary other studies in the literature reported $2.3-75 \%$ recurrences with postoperative radiotherapy ${ }^{[5,27,36,37]}$. In literature options regarding postoperative radiotherapy are general equivocal ${ }^{[5,29,30,36]}$. In our series all the cases with bone erosion and five patients from the recurrence ?? who underwent radiotherapy the tumors were not relapsed.

\section{Conclusions}

Giant cell tumor of tendon sheath of the hand is a common tumor. Magnetic resonance imaging is a diagnostic tool defining the location, extension, growth characteristic of the lesion and managing the preoperative planning. The tumor presents a high incidence of recurrence in different populations of patients. For this reason the risks factors of recurrences must be decreased with excised an block the tumor, dissection must be under surgical loop to discover and remove satellite lesion, protect the neurovascular elements, reconstruct the pulley system and when patients present increased risk factors or inadequate excision of the mass to perform postoperative radiotherapy. Patients should be informed about the high percentage of recurrence of the tumor even in complete excision and that should be considered in postoperative reexaminations.

\section{Ethical Approval}

Our institution does not require ethical approval for reporting individual cases or case series.

\section{Consent Form}

Verbal informed consent was obtained from the patient for their anonymized information to be published in this article. 


\section{Conflict of interest}

The authors declare that have no conflict of interest.

\section{Funding Statement}

There was no financial support for research and publication of this article.

\section{References}

[1] Darwish FM, Haddad WH. Giant cell tumor of tendon sheath: experience with 52 cases. Singapore Med J 2008;49:879-82.

[2] Monaghan H, Salter DM, Al-Nafussi A. Giant cell tumor of tendon sheath (localised nodular tenosynovitis): clinicopathological features of 71 cases. J Clin Path 2001;54(5):404—7, doi:10.1136/jcp.54.5.404.

[3] Lucas DR. Tenosinovial giant cell tumor: case report and review. Arch Pathol Lab Med. 2012;136:901-6, doi:10.5858/arpa.2012-0165-CR

[4] Koutserimpas C, Kastanis G, Ioannidis A, Filippou D, Balalis K. Giant cell tumors of the tendon sheath of the hand: an 11-year retrospective study. J BUON. 2018;23:1546-51.

[5] Fotiadis E, Papadopoulos A, Svarnas T, Akritopoulos P, Sachinis NP, Chalidis BE. Giant cell tumor of tendon sheath of the digits. A systematic review. Hand. 2011;6:244-9, doi:10.1007/s11552-011-9341-9

[6] Suresh SS, Zaki H. Giant cell tumor of tendon sheath: case series and review of literature. J Hand Microsurg 2010;2:67-71, doi:10.1007/s12593-010-0020-9.

[7] Van der Heijden L, Gibbons CLMH, Dijkstra PDS, et al. The management of diffuse-type giant cell tumour (pigmented villonodular synovitis) and giant cell tumour of tendon sheath (nodular tenosynovitis). J Bone Joint Surg Br 2012;94(7):882-8, doi:10.1302/0301620X.94B7.28927.

[8] Muthu A, Annamalai S, Thakur A, Ramakrishnan E. Recurrence free management of type 2 variant of giant cell tumour of extensor tendon sheath of thumb. BMJ Case Rep. 2020;13(10): e235762, doi:10.1136/bcr-2020235762

[9] Hamdi MF, Touati B, Zakhama A . Giant cell tumour of the flexor tendon sheath of the hand. Musculosketal Surg 2012;96(1):29-33, doi:10.1007/s12306-011-0148-1.

[10] Gouin F, Noailles T. Localized and diffuse forms of tenosynovial giant cell tumor (formerly giant cell tumor of the tendon sheath and pigmented villonodular synovitis). Orthop Traumatol Surg Res. 2017;103(1S):S91-7, doi:10.1016/j.otsr.2016.11.002.

[11] Lancigu R, Rabarin F, Jeudy J, Sant Cast Y, Cesari B, Fouque PA, Raimbeau G. Giants cell tumors of the tendon sheaths in the hand: Review of 96 patients with an average follow-up of 12 years. Orthop Traumatol Surg Res. 2013;99(4suppl):s251-251, doi:10.1016/j.otsr.2013.03.008.

[12] Al-Qattan M. Giant cell tumors of tendon sheath: clas $\neg$ sification and recurrence rate. J Hand Surg 2001;26(1):72-5 doi:10.1054/jhsb.2000.0522.

[13] Reilly KE, Stern PJ, Dale JA. Recurrent giant cell tumors of the tendon sheath. J Hand Surg Am. 1999;24:12981302. doi: 10.1053/jhsu. 1999.1298
[14] Chassaignac M. Cancer de la gaine des tendons. Gazette Hop Civils Mil 1852;47:185-6.

[15] Targett JH. Giant cell tumors of the integument. Trans Pathol Soc Lond 1897;48:230 — 5.

[16] Lanzinger WD, Bindra R. Giant cell tumor of the tendon sheath, J Hand Surg Am. 2013;38(1):154-157, doi:10.1010/j.jhsa.2012.11.001.

[17] Durmus M, Yapici AK, Avsar S, Yigit N, Bayram Y. Giant cell tumor of the tendon sheath restricting joint movement in the thumb: A case study and review of literature. Hand Microsurg. 2015;4:16-19, doi:10.5455/handmicrosurg. 172981.

[18] Rao AS, Vigorita VJ. Pigmented villonodular synovitis (giant cell tumor of the tendon sheath and synovial membrane). A review of eighty one cases. J Bone Joint Surg Am, 1984;66(1):76-94.

[19] Glowacki KA, Weiss AP. Giant cell tumors of ten $\neg$ don sheath. Hand Clin 1995;11:245-53.

[20] Grover R, Grobbelaar AO, Richman PI, et al. Measurement of invasive potential provides an accurate prognostic marker for giant cell tumour of tendon sheath. J Hand Surg Br. 1998;23:728-

[21] Kay RM, Eckardt JJ, Mirra JM. Multifocal pigmented villo-nodular synovitis in a child. A case report. Clin Orthop 1996; 322:194-7.

[22] Martinoli C, Bianchi S, Derchi LE. Tendon and nerve sonography. Radiol Clin North Am 1999;37:691-711.

[23] Levi M, Crafton J. Rare Giant Cell Tumor of the distal flexor digitorum longus tendon sheath and early diagnosis with use of magnetic resonance imaging. J Am Podiatr Med Assoc 2017;107:333-6.

[24] Lautenbach M, Kim S, Millrose M, Eisenschenk A. Nodular giant cell tumour of the tendon sheathof the hand: Analysis of eighty-four cases: Diagnostic decisions and outcome. Int Orthop2013;37:2211-5.

[25] Ikeda K, Osamura N, Tomita K. Giant cell tumour in the tendon sheath of the hand: importance of the type of lesion. Scand J Plast Reconstr Surg Hand Surg 2007;41:138-142

[26] Wang C, Song RR, Kuang PD, Wang LH, Zhang MM. Giant cell tumor of the tendon sheath: Magnetic resonance imaging findings in 38 patients. Oncot Lett. 2017;13(6):4459-4462, doi:10.3892/ol.2017.0611.

[27] Kotwal PP, Gupta V, Malhotra R. Giant-Cell tumour of the tendon sheath. Is radiotherapy indicated to prevent recurrence after surgery? J Bone Joint Surg $\mathrm{Br}$ 2000;82:571-3.

[28] Lorea P, Van De Walee H, Kinner L, Ledoux P, Moermans JP, Van De Heule B. Giant cell tumours of tendon sheath: lack of correlation between nm23 - H1 expression and recurrence. $\mathrm{J}$ Hand Surg $\mathrm{Br}$ 2004;29(1):67-70, doi: 10.1016/s0266-7681(03)00222-5

[29] Di Grazia S, Succi G, Fraggetta F, Perrotta RE. Giant call tumor of tendon sheath: Study of 64 cases and review of literature. G Chir2013;34:149-52.

[30] Ozben H, Coskun T. Giant cell tumor of tendon sheath in the hand: analysis of risk factors for reccurence in 50 cases. BMC Musculoskelet Disord.2019;20;457, doi:10.1186/s12891-019-2866-8

[31] Dhaniwala MN, Dhaniwala NS, Ahmed A. A case report of giant cell tumor of the flexor tendon sheath in index finger, J Orthop Case Rep 2020;9(6):78-81, doi: 10.13107/ocr.2019.v09.i06.1598. 
[32] Kitagawa Y, Ito H, Yokoyama M, et al. The effect of cellular proliferative activity on recurrence and local tumour extent of localized giant cell tumour of tendon sheath. J Hand Surg Br.2004;29:604-7.

[33] Williams J, Hodari A, Janevski P, Siddiqui A. Recurrence of giant cell tumors of the hand: a prospective study. J Hand Surg Am. 2010;35:451-6.

[34] Jaffe HL, Lichtenstein L, Sutro CJ. Pigmented villonodularsynovitis, bursitis and tenosynovitis. Arch Pathol 1941;31:371.
[35] Frank MK, Doris EW, Carrie YI, Peter SR, Franklin HS. Giant cell tumor of bone: Risk factors for recurrence. Clin Orth Relat Res 2011;469:591-9.

[36] Garg B, Kotwal PP. Giant cell tumour of the tendon sheath of the hand. J Orthop Surg. 2011;19:218-20.

[37] Ushijima M, Hashimoto H, Tsuneyoshi M, et al. Giant cell tumor of the tendon sheath (nodular tenosynovitis). A study of 207 cases to compare the large joint group with the common digit group. Cancer. 1986;57:875-84. 